\title{
How do HRM practices improve employee satisfaction?
}

\author{
Hauret, Laetitia^; Martin, Ludivine^^^; Omrani, Nessrine`; Williams, Donald R.^^ \\ "LISER - Luxembourg Institute of Socio-Economic Research \\ * CREM - Center for Research in Economics and Management (UMR CNRS 6211), Rennes, France \\ - Paris School of Business \\ - KENT State University \\ Pre-copyedit version of the paper published in Economic and Industrial Democracy, First Published \\ October 14, 2020, https://doi.org/10.1177/0143831X20962199
}

\begin{abstract}
:
Using employer-employee data, this paper studies the relationships between the bundle of Human Resource Management (HRM) and job satisfaction. By simultaneously integrating employee HRM exposure and HRM perception, which remains scarce in the literature, we find that a high HRM exposure is not sufficient to improve job satisfaction when employee HRM perception is taken into account. Moreover, we highlight that differences in the level of employee HRM perception, contrary to the level of exposure, influence the way employees react to their personal, job and workplace characteristics. The results suggest a role of managers to strengthen employee positive HRM perception to improve job satisfaction.
\end{abstract}

Keywords: Job satisfaction; Actual HRM practices; Perceived HRM practices; Employer-employee data; Working conditions 


\section{Introduction}

Employing happy employees at work is a crucial issue for firms. Happier employees tend to be more creative, performant and productive, which ultimately generate and sustain improved business performance (e.g. Brown et al., 2011; Huang et al., 2016; Wood et al., 2012; Zelenski et al., 2008). ${ }^{1}$ Consequently, managers must ask themselves how to increase employees' well-being.

In this context, the role of HRM practices on employee well-being has been examined in the literature (see for instance the meta-analyses provided by Jiang et al., 2012 and Markoulli et al., 2017). Studies show mixed results in this regard depending on the HRM practices studied. On the one hand, some studies conclude there is a negative link between HRM practices and employees' job satisfaction (Askenazy and Caroli, 2010; Frick et al., 2013; Green, 2006). These studies argue that HRM practices (e.g. performance relative pay, job rotation, teamwork) lead to work intensification which increases job strain, accidents at work or absenteeism. On the other hand, other studies conclude there is a positive link between some HRM practices (e.g. flexible work practices, performancerelated pay, training, information sharing) and job satisfaction (Green and Heywood, 2008; Kalmi and Kauhanen, 2008; Kröll and Nüesch, 2019; Tabvuma et al., 2015). Utilizing the bundle approach, which posits that coherent HRM practices need to be adopted together to obtain the highest benefits for the firm and employees (e.g. Becker et al., 1997; Becker and Huselid, 1998; Gerhart, 2007), other studies also conclude there is a positive link between the bundle of HRM practices and job satisfaction.

The analysis of how bundles of HRM practices affect employees has been conducted at various levels (e.g. organization, individual). At the organizational level, scholars have examined the relationship between employee attitudes and the actual implementation of HRM practices (e.g. Huang et al., 2016; Ogbonnaya et al., 2017; White and Bryson, 2013). They suggest that the adoption of a bundle of HRM practices by the organization is positively related to employee attitudes. ${ }^{2}$ Another strand of literature focuses on the perception of individual employees about HRM practices (e.g. Chowhan et al., 2016; Godard, 2010). ${ }^{3}$ According to the theory of HR attributions (e.g. Hewett et al., 2018; Nishii et al., 2008), perception is important to take into account as employees react differently to HRM practices according to their beliefs about the employers' motivations to implement them. Empirical studies show a positive relationship between perception and employee attitudes (e.g. Kehoe and Wright, 2013; Nie et al., 2018; Van de Voorde and Beijer, 2014). 
As employees' perceptions of HRM practices were shown to vary significantly from employers' assessments of HRM practices actually in use (e.g. Liao et al., 2009), it is necessary to integrate both levels of analysis in a single study by examining the relationships between HRM exposure and HRM perception with job satisfaction jointly. The integration of these two levels enables researchers to know whether the implementation of managerial practices is sufficient to increase employees' job satisfaction or whether employees have to appropriate them. To date, less than $3 \%$ of the 495 empirical studies analysing HRM consequences provide a multi-level analysis (Boon et al., 2019).

Previous studies (e.g. Den Hartog et al., 2013; Edgar and Geare, 2005) provide evidence based on small samples or focused on a single sector or on one firm, which makes it difficult to generalize the evidence more broadly. The current study analyses data for a relatively large sample of employers and employees. Moreover, we proceed step by step to identify the extent to which the degree of a set of HRM practices applied by managers, independent of the perception by employee, are related to job satisfaction. The strength of the links between job satisfaction and exposure to managerial practices and perception of these practices are important to study. Indeed, the strength of these links has managerial implications. It helps managers to identify if their efforts, in the aim of increasing employees' well-being, should be limited to the implementation of HRM practices or if they should also relate to the appropriation of these practices by their employees. Moreover, it is important to know the mechanisms by which HRM practices affect employee's job satisfaction. For example, does high exposure to an HRM set of practices or high perception modify the way employees react to their working conditions?

Our analysis is based on linked employer-employee data collected in a small, open European country characterized by the predominance of its service sector, namely Luxembourg. The dataset constitutes a representative sample of employees of the private sector working in workplaces of at least 15 employees. Due to the specificity of the Luxembourgish labour market characterized by a large proportion of foreign employees, the results are obtained not only for Luxembourgish employees but also for cross-border and migrant employees from France, Belgium, Germany and Portugal.

This paper contributes to the literature in several ways. First, we investigate the relationships between sets of HRM practices and job satisfaction using two levels of analysis, HRM exposure and HRM perception, and provide new knowledge regarding the internal fit of HRM bundles, specifically on the alignment of employer and

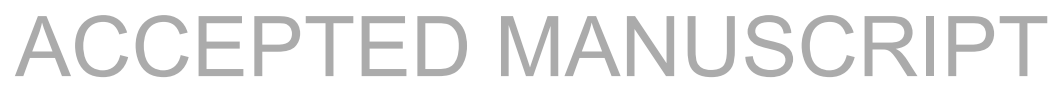


employee views. Second, the data used covers a large number of firms and employees across several sectors of the economy. Third, it employs multiple regression methods allowing for a wide range of control variables not used in the previous work. Fourth, we deepen the examination of differences in job satisfaction, using a decomposition method (Oaxaca-Blinder), by comparing groups who face different levels of HRM exposure and who have different levels of HRM perception. More precisely, we identify how much of the difference in job satisfaction between groups is due to the fact that (i) they have different characteristics (personal, occupational and workplace) or (ii) they value these characteristics differently.

The results support integrating both levels of analysis in the study of employee attitudes. They indicate that a high level of exposure to HRM is not sufficient to improve employee attitudes; effective participation that goes through a positive evaluation of HRM by employees is required. HRM research and managers need to put in the forefront of their priority employees' perceptions of HRM. HRM practices can enhance job satisfaction only if employees endorse HRM (e.g. Hewett et al., 2018; Nishii et al., 2008). Moreover, our results show that the differences in employee HRM perception affect the way they react to their personal, job and workplace characteristics.

The paper proceeds as follows. Section 2 defines concepts, reviews the existing literature and develops hypotheses. Section 3 describes the data, the variables and the estimation strategy. Section 4 presents the results. Section 5 concludes, with a discussion of limitations and topics for further research.

\section{Concepts and existing evidence}

\subsection{Analytical framework}

Several analytical frameworks have been developed to explain how HRM practices relate to firm performance and employee well-being. Given the breadth of each of these frameworks, we provide here an illustrative rather than an exhaustive discussion of existing approaches.

First, in the tradition of the AMO model (Appelbaum et al., 2000), employers adopt HRM practices that strengthen employees' abilities, motivation and opportunity to contribute, in order to positively influence their performance (see for a review Subramony, 2009). Second, in the resource-based view of the firm tradition (Barney, 1991; Barney and Wright, 1998), employers invest in HRM practices in order to develop and utilize human capital of

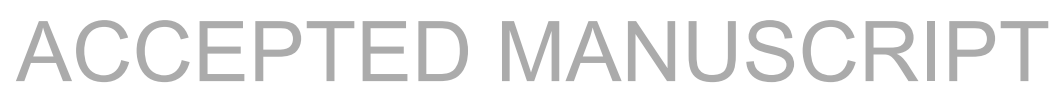


their workforce for the benefit of the firm. Third, the PIRK model (Lawler, 1986) states that providing employees sufficient power, information, reward and knowledge will enhance firm performance. These approaches have been used by some studies to explore well-being (e.g. see the meta-analysis provided by Jiang et al., 2012 or the paper by Chowhan et al., 2016).

Other analytical frameworks give greater priority to employees and explore how HRM practices improve wellbeing that in turn should increase firm performance. The main underlying assumption in these frameworks is that employees react positively to a positive work environment built by the employer through the implementation of HRM practices.

First, in the job demands-resources model (Bakker and Demerouti, 2007; Schaufeli and Bakker, 2004) HRM practices act as a resource to balance job demands costs (e.g. workload, emotional demands). Second, in the vitamin model (Warr, 1987), HRM practices act as vitamins on employees to improve their well-being, although defining the appropriate 'dose' is important to avoid abuse. Third, in the mutual gains approach (Batt, 2004; Kalmi and Kauhanen, 2008; Osterman, 2000), employers through their investment in HRM practices enhance the quality of the work environment in order to convince employees that their contributions are recognized. Fourth, in the psychological contract approach (Rousseau, 1995; Sturges et al., 2005; Suazo et al., 2009), the HRM practices adopted by the employer define the psychological contract by influencing employer and employee promises fulfilment. Fifth, in the tradition of the social exchange theory (Blau, 1964), the HRM practices shape a positive exchange relationship implying a high level of trust, fairness, the balance of employer and employee interests, and giving voice to employees. Grounded on these analytical frameworks, Guest (2017) developed an original approach supposing mutuality and a positive employment relationship. It suggests a balanced mutual exchange between employees and employer and the reciprocity of employees to the positive employment relationship (Gould-Williams, 2007).

\subsection{Components of the HRM system}

The scope of HRM practices that are included in the HRM system and studied in the literature is not described by either a common set of covered practices or a common terminology (e.g. High-Performance Work Practices HPWP, Alternative Work Practices - AWP). The HRM practices found in the literature mostly cover a) participation in the organizational life, b) team work, c) development, d) job security, e) family-friendly practices, 
f) incentives and g) selection (e.g. Godard, 2010; Mohr and Zoghi, 2008; Ramsay et al., 2000; White and Bryson, 2013).

Participation in the organizational life practices (a) are practices through which employees can make their voice heard regarding their working conditions and/or the organization of the firm (e.g. meetings organized between managers and the staff) and actively contribute to modify them (e.g. quality circles) (e.g. McGovern et al., 2007). Team work (b) is related to positive reactions of employees (e.g. Batt, 2004; Hanaysha and Tahir, 2016). Team co-workers share at least part of the responsibilities for decision-making, giving them more discretion. Job rotation inside teams permits employees to learn new skills and knowledge, increases variability and gives more flexibility for managers to cover absences. HRM practices dedicated to development (c) increase workforce skills through training and appraisals (e.g. Boxall and Macky, 2009; Tabvuma et al., 2015). Appraisals allow managers to take time to discuss with each employee individual work, give feedback and propose further training if needed. Appraisals can also be used to define appropriate rewards included in the incentive domain. Practices improving job security (d) help to build a stable environment (through e.g. non-compulsory redundancies policies) in which employees can develop their skills (e.g. Ramsay et al., 2000). Family-friendly practices (e) such as flexible worktime schemes aim to support family roles and reduce work-family conflicts (e.g. Ernst, Kossek and Ozeki, 1998). In the incentive domain (f), pay incentive is a traditional practice to reward performance (Green and Heywood, 2008). Moreover, non-monetary or fringe benefits are part of modern compensation packages used by employers as a sorting tool to retain key employees, and to provide status and identity sharing (e.g. Eriksson and Kristensen, 2014). Selection of employees (g) during recruitment and the monitoring of this process to ensure no discrimination are also included in the scope of HRM in some papers (e.g. Combs et al., 2006).

\section{$2.3 \quad$ Bundle approach}

In order to obtain the highest benefits for the firm and employees, the bundle approach posits that HRM practices need to be adopted together (e.g. Bowen and Ostroff, 2004; Godard, 2004). This concept is termed 'bundle' since the works of Huselid (1995) and MacDuffie (1995). Looking at the HRM system as a whole allows taking into account the positive and negative complementarities between practices that is not possible when studying isolated individual HRM practices (e.g. Combs et al., 2006; Wood, 1999). According to the meta-analysis of Subramony (2009) done on 65 studies, HRM bundles were shown to have significantly larger magnitudes of effects than the individual practices that constitutes the bundles on various measures of business performance (e.g. operating 
performance, financial performance, and overall performance ratings). However, according to the fit approach (e.g. Kepes and Delery, 2009; MacDuffie, 1995) the bundle needs to be composed of a coherent system of HRM practices in order to generate positive synergistic effects and positive outcomes for firms and employees (e.g. Becker et al., 1997; Becker and Huselid, 1998; Gerhart, 2007). The fit approach (e.g. Kepes and Delery, 2009) distinguishes four internal fit perspectives and one external fit perspective. The external fit refers to the idea that the HRM system needs to be aligned with contextual factors of the firm (e.g. business strategy). Regarding the internal fit, the first perspective is the 'inter-HRM activity area fit', which refers to the fit between different HRM practices, where a coherent alignment between HRM practices induces 'powerful connections' while incompatible HRM practices form 'deadly combinations' that ultimately harm outcomes. Second, the 'intra-HRM activity area fit' is close to the 'inter-HRM activity area fit' and refers to the coherence between specific HRM practices within a certain HRM system (e.g. HRM practices within the compensation practice system). Third, the 'between-HRM system fit' is about the alignment of the various HRM systems that composed the HRM architecture of a firm. Fourth, the 'within-HRM system vertical fit' concerns the degree of fit between different HRM practices on diverse levels of abstraction, specifically the bundle of HRM practices adopted by employers to which employees are exposed and the practice level perceived by employees who faced the bundle adopted. By adding the employee view, this perspective of the fit approach relates to the theory of HR attributions (e.g. Hewett et al., 2018; Nishii et al., 2008), which posits that the employees' beliefs about the employers' motivations to implement HRM practices influence their reaction to HRM practices. A misfit between the two views could result in negative synergistic effects.

\subsection{Empirical evidence on the link between the bundle of HRM practices and job satisfaction}

Both levels of analysis of HRM exposure and HRM perception have been studied independently and/or jointly in the literature (see for instance the literature review provided by Van de Voorde et al., 2012). We only present the studies that use bundles of HRM practices in accordance with the approach chosen in this article (see Supplementary online material Table S.1 for an overview of the literature).

First, one strand of research focuses on the link between actual bundles of HRM practices implemented by businesses and their performance. Employees' job attitudes (e.g. job satisfaction, commitment) are only here mediating variables between the HRM set of practices and the firm's performance. In this perspective, it is the manager that reports about the actual HRM practices that employees are exposed to. A positive link between the

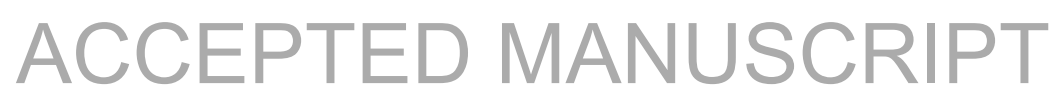


bundle of HRM exposure with job satisfaction is apparent across sectors, countries and sample characteristics (Godard, 2010; Hoque, 1999; Huang et al., 2016; Katou and Budhwar, 2006; Ogbannaya et al., 2017; Park et al., 2003; Ramsay et al., 2000; White and Bryson, 2013). White and Bryson (2013) highlight, however, a non-linear relationship: positive effects on job satisfaction appear only when a critical number of HRM practices are in place. Second, another strand of research focuses on the HRM perception by employees. The measure of perception is obtained from employees who report their participation in, for example, training, and their perception about, for example, the utility of information-sharing; the distributive, procedural and interactional justice behind the firm adoption; or the well-being and the performance motive of the manager (e.g. Kehoe and Wright, 2013; Nie et al., 2018; Van de Voorde and Beijer, 2014). Once again, a positive link of HRM bundle perception with job satisfaction is apparent across sectors, countries and sample characteristics (Böckerman et al., 2012; Boxall and Macky, 2014; Chowhan et al., 2016; Godard, 2001; Gould-Williams, 2003; Guest, 1999; Kalmi and Kauhanen, 2008; Macky and Boxall, 2007; Martin, 2018; Mohr and Zoghi, 2008; Nishii et al., 2008). However, some studies (e.g. Godard, 2001; Heffernan and Dundon, 2016; Macky and Boxall, 2007) highlight that the link between the number of HRM practices and job satisfaction is not monotonic. The positive link between HRM practices adoption by employees and job satisfaction disappears or becomes negative when the number of practices adopted by employees reaches a certain threshold. The adoption of many HRM practices is a source of complexity which can increase, according these authors, stress or overload which negatively impacts job satisfaction.

Third, a few papers include both HRM exposure and HRM perception in studies of employees' job satisfaction (Den Hartog et al., 2013; Edgar and Geare, 2005). Den Hartog et al. (2013), using a confirmatory factor analysis (CFAs), show that manager-rated HRM has no effects on job satisfaction when employee perceptions are taken into account. Edgar and Geare (2005) provide correlations. They are insignificant between employers' measures (both number of adopted practices and employers' assessment) and job satisfaction and positively significant between employees' HRM perception and job satisfaction. In the regression results they provide, the level of predictive power of employers' measures are close to zero while the level of predictive power of employees' measures are the variables with the greatest explanatory power. These results are not consistent with the strand of research that analyses actual HRM practices implemented by businesses that shows a positive link (see above). Moreover, the small number of firms included in their samples and their representativeness are questionable to 
generalize their evidence (53 firms for Edgar and Geare, 2005; 119 branches of a single restaurant for Den Hartog et al., 2013).

The existing empirical literature implies the following hypotheses to be examined in this paper:

Hypothesis 1: The degree of HRM exposure is positively related to job satisfaction.

Hypothesis 2: The degree of HRM perception is positively related to job satisfaction.

Hypothesis 3: The degree of HRM perception has a stronger relationship with job satisfaction than the degree of HRM exposure.

Testing the hypotheses above will indicate whether workers with different levels of exposure to or perception of HRM practices on average have different levels of job satisfaction. Another research question addressed in this paper is whether the differences in job satisfaction are the result on the one hand of differences in characteristics of the employees, their jobs or workplaces, or on the other hand of differences in the ways in which the employees react to their personal, job and workplace characteristics. It may be possible, for example, that the utilization of HRM in the firm leads to differences in its employee's reaction to their job characteristics. This leads to the final hypothesis to be studied.

\section{Hypothesis 4:}

Hypothesis 4a: Differences in job satisfaction associated with HRM perception or exposure are mainly explained by the endowment effect that is to say by differences in personal, job, and workplace characteristics.

Hypothesis $4 b$ : Differences in job satisfaction associated with HRM perception or exposure are mainly explained by the coefficient effect that is to say by differences in the way employee react to their personal, job and workplace characteristics.

To the authors' knowledge, there are no studies that look comprehensively at the relationships between the degree of exposure and the degree of perception in the bundle of HRM practices and job satisfaction.

\section{Data and methodology}

\subsection{Data}


The data used in this paper come from linking two nationally representative surveys in Luxembourg conducted in 2013. Although relatively old, these data have two advantages. First, they make it possible to have both employer and employee views on the same HRM practices which is scarce in datasets (Den Hartog et al., 2013; Edgar and Gear, 2005). Second, these data allow analyses to be carried out on larger samples of employees and firms across a variety of industries.

The collection of data followed the MEADOW Consortium (2010) guidelines. The employer survey, Enterprises Organizational and Managerial Practices survey (POME), consisted of a non-compulsory self-completion survey of the Human Resources Responsible of all workplaces with 15 or more employees in the private sector (with a response rate of 56\%). The employee survey, Working Conditions and Quality of Work Life survey (QVT), was sent to a stratified random sample of employees aged at least 16 years old and working at least six months in all workplaces with 15 or more employees in the private sector. The sample was drawn from the data register of the social security administration of Luxembourg and employees were contacted at their personal home addresses. This survey was an online non-compulsory self-completion survey (with a response rate of $26 \%$ ). Due to the uniqueness of the Luxembourgish labour market characterized by a large proportion of cross border employees, which represent $53 \%$ of the working population (in the private sector in 2013), the employee survey was conducted in four countries (Luxembourg, France, Germany and Belgium) and three languages (French, German and English). Due to the absence of linked employee or employer data in some cases, the effective samples used in this paper are 1,238 employers and 8,373 employees. The database includes weights used to ensure representativeness of employees working in firms with 15 or more employees and of firms.

\subsection{Dependent variable}

The dependent variable used here is job satisfaction, i.e. the hedonic part of psychological well-being (Guest, 2017; Warr, 1990). Our overall measure is based on those commonly used in the literature (e.g. Clark, 2001). The variable is based on a question asked of employees: 'How satisfied are you with your work?', with responses ranging from 0 (“completely dissatisfied") to 10 (“completely satisfied"). The mean of the job satisfaction measure is 6.30 with a standard deviation of $2.18 .^{4}$

\subsection{Measures of HRM}


We use the bundle perspective, and more precisely the most common, namely additive, approach (Edgar and Geare, 2005), to characterize HRM exposure and HRM perception (see Table 1). The HRM practices included in our bundle are close to those used in the literature and cover participation in the organizational life, team working, development, family-friendly practices and incentives (e.g. Macky and Boxall, 2007; Mohr and Zoghi, 2008; White and Bryson, 2013). Some HRM practices included in the existing literature are not covered in our analysis mainly due to non-relevance regarding the aim of our analysis and/or the Luxembourgish context. This is the case, firstly, for the practices that refer to the screening and selection process of employees. While these practices may have an effect on performance, by selecting better employees, they should not influence incumbent employees who already work for the firm. Secondly, the practices related to job security and non-compulsory redundancies policy are not relevant in the Luxembourgish context, which is characterized by strict employment protection both at the individual and collective levels. ${ }^{5}$

Table 1. HRM practices included in the HRM bundle

\begin{tabular}{llcc}
\hline Domain name & Contents & $\begin{array}{c}\text { Employer } \\
\text { (exposure) } \\
\text { mean }\end{array}$ & $\begin{array}{c}\text { Employee } \\
\text { (perception) } \\
\text { mean }\end{array}$ \\
\hline & & $(1)$ & $(2)$ \\
\hline Participation in & Meeting between management and the staff & $66.8 \%$ \\
the organizational & Changes with employees involved & $79.6 \%$ & $13.4 \%$ \\
life & Attitude surveys & $87.6 \%$ & $42.1 \%$ \\
& Quality circle & $36.5 \%$ & $24.3 \%$ \\
\hline Team working & Autonomous team work & $31.6 \%$ & $30.9 \%$ \\
& Job rotation & $28.3 \%$ & $51.3 \%$ \\
\hline Development & Development included in the strategy & $82.7 \%$ & $53.7 \%$ \\
& Training & $42.1 \%$ & $42.1 \%$ \\
& Appraisal & $26.2 \%$ & $58.3 \%$ \\
\hline Family-friendly & Flexible working hours & $46.1 \%$ & $39.4 \%$ \\
& Work-life balance & $20.7 \%$ & $39.4 \%$ \\
& Work at home during work hours & $21.9 \%$ & $7.7 \%$ \\
\hline Incentives & Individual pay incentive & $19.9 \%$ & $32.4 \%$ \\
& Fringe benefits & $65.1 \%$ & $49.6 \%$ \\
\hline HRM bundle & Sum of the 14 HRM practices & $70.8 \%$ & 5.5 \\
& & 6.6 & $(2.76)$ \\
& & {$[7]$} & $(2.6)$ \\
\hline Observations & & $\alpha=0.74$ & $\alpha=0.67$ \\
\hline
\end{tabular}

Sources: Employer-employee database - Luxembourg - 2013

Notes: Standard deviations are reported in parentheses, median values in brackets for non-binary variables and $\alpha$ for Cronbach's alpha. Reading guide: In $70.8 \%$ of workplaces, a fringe benefits system, is set up for all or part of their staff. $49.6 \%$ of employees declare that they obtain fringe benefits. 
The means presented in Table 1 measure in column (1) the percentage of workplaces that have implemented the HRM practice as assessed by employers and in column (2) the percentage of employees who declared their positive perception about a practice (Supplementary online material Table S.2 provides details about the measure of each HRM practice). The values for 'HRM bundle' are the average for the sum of the HRM practices at the workplace and the employee levels. That is, for a given workplace, "HRM bundle" represents the number of HRM practices implemented by the employer (to all employees for some practices such as meetings between management and the staff, and to at least $25 \%$ of the employees for some practices such as autonomous team work). For a given employee, "HRM bundle" measures the number of practices in which the employee has a positive perception. A comparison of the means [and medians] reveal the distributions are slightly skewed. The consistency of Cronbach's alpha are acceptable (Hair et al., 2006).

We separate workplaces into two groups (high and low exposure) and employees into two groups (high and low positive perception) using the median values of the bundles as cut-offs. ${ }^{6}$ These median values are calculated at the sectoral level to account for the fact that HRM strategies may differ by sector as shown by Arundel et al. (2007). We then define four employee-employer groups using these cut-offs: 'Exposure low \& perception low' (LL); 'Exposure high \& perception low' (HL); 'Exposure low \& perception high' (LH) and 'Exposure high \& perception high' (HH). Those classified as LL therefore have below-the-median levels of both exposure and perception, whereas those classified as HH have above-the-median levels of both. In order to compare with previous work, we also created variables indicating a high level of exposure (regardless of the level of perception), $\mathrm{EH}$, and a high level of perception (regardless of the level of exposure), $\mathrm{PH}$. We see in Table 2 that nearly 59\% of employees work in a firm that offers a high level of exposure to HRM, and 54\% of employees report a high perception level. We also see that $17.5 \%$ of employees belong to the 'Exposure low \& perception high' (LH) group. These employees work in a workplace where the number of actual HRM practices is lower than the median of the sector (not a direct comparison between HRM exposure and HRM perception in each firm). They are therefore less exposed to HRM practices compared to other employees working in the same sector. But when the practices are available, they reach a level of positive perception that is higher than the median of the employees belonging to the same sector. 
Table 2. Distribution of the exposure-perception groups

\begin{tabular}{llc}
\hline Groups & & $\begin{array}{c}\text { Employee } \\
\text { level }\end{array}$ \\
\hline EH & Exposure high & $58.7 \%$ \\
\hline PH & Perception high & $54.3 \%$ \\
\hline LL & Exposure low \& perception low & $23.8 \%$ \\
\hline HL & Exposure high \& perception low & $21.9 \%$ \\
\hline LH & Exposure low \& perception high & $17.5 \%$ \\
\hline HH & Exposure high \& perception high & $36.8 \%$ \\
\hline Observations & & 8,373 \\
\hline
\end{tabular}

Sources: Employer-employee database - Luxembourg - 2013

\subsection{Control variables}

The control variables, included in all the analyses, are like those used in the literature focusing on job satisfaction (e.g. Bryson and White, 2016; Clark et al., 1996; Clark, 1997; Gazioglu and Tansel, 2006; Hauret and Williams, 2017; Kifle, 2014; Raab, 2020; Sousa-Poza and Sousa-Poza, 2000; Stutzer and Frey, 2008). Online supplementary material Table S.3 presents these variables and provides descriptive statistics comparing the characteristics of employees, their job and their workplace related to their exposure-perception group. The descriptive statistics reveal that the mean values for the high-high $(\mathrm{HH})$ category of workers differ from the other categories for several variables (e.g. higher level of education, more often in a professional or managerial occupation, better paid, work in larger organization). These differences imply the need to carefully control for individual, occupational and workplace characteristics.

\subsection{Estimation strategy}

The measure of job satisfaction is treated as a continuous dependent variable. We use linear regression to estimate the coefficients. An alternative specification, using an ordered probit, is also estimated as a robustness check, described below. Robust standard errors are clustered at the organization level to correct for the fact that multiple employees can be employed by the same organization and therefore the observations are not entirely independent. ${ }^{7}$

In a first step, we analyse the relationship between job satisfaction and HRM exposure or HRM perception taken individually. The parameters of the following models are estimated:

$Y_{i}=H R M_{i} \beta_{1}+X_{i} \beta_{2}+\varepsilon_{i}$ 
where $Y_{i}$ is the level of job satisfaction of individual i, HRMi, indicates HRM exposure or HRM perception measured at the employer or employee level, $X_{i}$ a vector of the individual, occupational and workplace characteristics (and a constant), $\beta$ is the vector of coefficients and $\varepsilon_{i}$ is a normally distributed random error term. In a second step, we include both levels of analysis, to see if the results are consistent with the existing literature. We begin with a model introducing HRM exposure and HRM perception taken jointly and we estimate the parameters of the following model:

$Y_{i}=E H_{i} \beta_{1}+P H_{i} \beta_{2}+X_{i} \beta_{3}+\varepsilon_{i}$

where $Y_{i}$ is the level of job satisfaction of individual i, EHi, and $P H i$ indicate high levels of exposure or perception, respectively, $X_{i}$ a vector of the individual, occupational and workplace characteristics (and a constant), $\beta$ is the vector of coefficients and $\varepsilon_{i}$ is a normally distributed random error term.

In order to go further we use dummy variables indicating the exposure-perception groups $\left(L L_{i}, H L_{i}, L H_{i}\right.$, with $H H_{i}$ as the reference group) and estimate the following model:

$Y_{i}=L L_{i} \beta_{1}+H L_{i} \beta_{2}+L H_{i} \beta_{3}+X_{i} \beta_{4}+\varepsilon_{i}$

where $Y_{i}$ is the level of job satisfaction of individual i, $L L_{i}, H L_{i}, L H_{i}$ indicate the exposure-perception groups, $X_{i}$ a vector of the individual, occupational and workplace characteristics (and a constant), $\beta$ is the vector of coefficients and $\varepsilon_{i}$ is a normally distributed random error term.

The high-high $(\mathrm{HH})$ category is chosen as the reference group in accordance with the J-shaped relationship between the number of HRM practices and job satisfaction shown by White and Bryson (2013). Moreover, in our sample high-high $(\mathrm{HH})$ is the most common category. As is noted above, the four exposure-perception categories vary considerably in the values of some of the explanatory variables.

In a third step, in order to measure the extent to which these differences in explanatory variables contribute to the overall differences in job satisfaction, we conduct a decomposition analysis (a variant of the Blinder (1973) and Oaxaca (1973) decomposition done by Daymont and Adrisani (1984)).

In order to do so, we estimate the same regressions as the latter but separately by exposure-perception groups (and without the dummy variables identifying groups): 
$Y_{i j}=X_{i j} \beta_{j}+\varepsilon_{i j}$

where $Y_{i j}$ is the level of job satisfaction of individual $i$ of group $j\left(j=\mathrm{LL}, \mathrm{LH}, \mathrm{HL}, \mathrm{HH}\right.$ ), $X_{i j}$ is a vector containing the values of individual, occupational and workplace characteristics for individual $i$ of group $j$ and the intercept, $\beta_{j}$ is the vector of coefficients for group $j$, and $\varepsilon_{i j}$ is the random error term normally distributed. In this analysis, the coefficients for the characteristics are allowed to vary across groups. ${ }^{8}$

The results from these models are used to decompose the employee differences in job satisfaction into three components. The first is the part of the difference that is attributable to differences in individual, occupational and workplace characteristics between the groups (called 'endowments effects'). The second is the part that is attributable to differences in the coefficients $(\beta)$ on those characteristics (called 'coefficients effects'). The third is the part that is attributable to the simultaneous effect of differences in the two first parts (called 'interaction'). Taking the example of the low-low employee group and keeping 'high-high' (HH) as the reference group, the decomposition is based on constructing the counterfactual asking first, what would the level of job satisfaction be for low-low employees if they had the same individual, occupational and workplace characteristics as high-high employees, and, second, what would the level of job satisfaction be for low-low employees if they placed the same value on characteristics as high-high employees?

The specification for the decomposition is the following:

$E\left(Y_{H H}\right)-E\left(Y_{L L}\right)=\left[E\left(X_{H H}\right)-E\left(X_{L L}\right)\right]^{\prime} \beta_{L L}+E\left(X_{L L}\right)^{\prime}\left(\beta_{H H}-\beta_{L L}\right)+\left[E\left(X_{H H}\right)-E\left(X_{L L}\right)\right]^{\prime}\left(\beta_{H H}-\beta_{L L}\right)$

The first term on the right-hand side is the part attributable to differences in the outcome variable between the two groups that is due to differences in the covariates $X$ (endowment effect). The second term is the part attributable to differences in the valuation of personal, occupational and workplace characteristics (coefficient effect). The third part is the interaction term. We present estimates of these components for job satisfaction by comparing each group with the reference group (high-high). The estimates allow tests of the hypotheses $4 \mathrm{a}$ and $4 \mathrm{~b}$.

Robust standard errors are clustered at the workplace level to correct for the fact that some employees are employed by the same workplace.

\section{Results}

\subsection{Exposure and perception taken individually}


We estimate regressions similar to those found in the literature regarding exposure and perception taken individually, as in Equation (1) above. The estimated coefficients for the key variables of interest are presented in Table 3. ${ }^{9}$ The F-test and R-squared measures indicate that the models perform well. Model A shows the coefficients for variables measuring HRM exposure, using job satisfaction measured at the employee level as in Huang et al. (2016) or Ogbonnaya et al. (2017). The results indicate that a High (above the median) level of exposure is positively related to job satisfaction. This result is consistent with those presented in the literature (e.g. Huang et al. 2016; Ogbonmaya et al., 2017) and Hypothesis 1.

Table 3. Regressions of job satisfaction on HRM exposure or HRM perception

\begin{tabular}{lcc}
\hline & Model A & Model B \\
\hline Exposure High (EH) & & \\
& $0.17^{* *}$ & \\
\hline Perception High (PH) & $(0.07)$ & $1.33^{* * *}$ \\
& & $(0.06)$ \\
\hline Individual characteristics & & Yes \\
Occupational characteristics & Yes & Yes \\
Workplace characteristics & Yes & Yes \\
\hline F-test & Yes & $25.54^{* * *}$ \\
R-squared & $9.19^{* * *}$ & 0.156 \\
Observations & 0.076 & 8,373 \\
\hline
\end{tabular}

Sources: Employer-employee database - Luxembourg - 2013

Notes: *Statistically significant at the .10 level; ** at the .05 level; *** at the .01 level.

Model B shows the coefficients for variables measuring HRM perception. Not controlling for the level of exposure, again we find results broadly consistent with the literature (e.g. Chowhan et al., 2016; Mohr and Zoghi, 2008). That is, a High (above the median) level of HRM positive perception is positively associated with job satisfaction as stated in Hypothesis 2.

\subsection{Exposure and perception taken jointly}

The results differ, however, when we include both exposure and perception in one analysis as in Equation (2). The results for the key variables are presented in Table $4 .{ }^{10}$ The F-test and R-squared measures indicate that the model performs well for both specifications. Note that, in column 1, when controlling for the level of perception, the level of exposure has a much smaller and insignificant coefficient consistent with existing results (Den Hartog 
et al., 2013; Edgar and Geare, 2005) but that does not support Hypothesis 1. When controlling for the level of exposure, the level of perception is still significant, validating Hypothesis 2. In line with Hypothesis 3, it appears, therefore, that exposure measures may simply serve as a weak proxy for employee perception in determining job satisfaction.

Table 4. Regressions of job satisfaction on exposure/perception to HRM

\begin{tabular}{lcc}
\hline & $(1)$ & $(2)$ \\
\hline Exposure High (EH) & 0.04 & $(0.07)$ \\
Perception High (PH) & $1.33^{* * *}$ & $(0.06)$ \\
& & $-1.38^{* * *}$ \\
\hline Exposure low \& perception low (LL) & & $(0.09)$ \\
Exposure high \& perception low (HL) & $-1.26^{* * *}$ \\
& & $(0.08)$ \\
Exposure low \& perception high (LH) & 0.04 \\
& & $(0.08)$ \\
\hline Individual characteristics & Yes \\
Occupational characteristics & Yes & Yes \\
Workplace characteristics & Yes & Yes \\
\hline F-test & $25.05 * * *$ & $24.77^{* * *}$ \\
R-squared & 0.156 & 0.156 \\
Observations & 8,373 & 8,373 \\
\hline
\end{tabular}

Sources: Employer-employee database - Luxembourg - 2013

Notes: *Statistically significant at the .10 level; ** at the .05 level; *** at the .01 level.

This is further confirmed when the measures are combined as in Equation (3) above (Table 4 column 2). Compared with high-high employees (high exposure and high perception - HH), a low HRM perception irrespective of the level of exposure is negatively associated with job satisfaction. Conversely, a high HRM perception while the workplace does not provide a high exposure is not statistically different from the high-high employees. The results highlight the importance of taking into account the level of employee HRM perception in order to understand the relationships between HRM practices and job satisfaction as underlined by the theory of HR attributions (e.g. Hewett et al., 2018; Nishii et al., 2008). This result joins the research of Koys (1991) and Peccei and Van de Voorde (2019) which show that the link between HRM practices implemented by the organization and employee attitudes depends on employees' perception. Regarding the fit approach (e.g. Kepes and Delery, 2009; MacDuffie, 
1995), and the 'within-HRM system vertical fit' approach which focuses on the degree of fit between different HRM practices on diverse levels of abstraction (employers and employees' views), the results highlight the dominance of the employee view when a misfit between both views appears. Therefore, when the exposure level exceeds the perception one (high-low), the misfit produces a detrimental effect on job satisfaction. In contrast, when the perception level exceeds the exposure one (low-high), the misfit has no effect. Employees need to participate in training, exercise voice during meetings between the staff and managers, participate in the decisionmaking process at the team level in order to support an improvement of their skills, knowledge and beyond to be satisfied and respond positively to the HRM system in place no matter the level of HRM exposure they face.

\subsection{Decomposition analysis}

As previously mentioned, and supported by the results in Table 4, a significant job satisfaction gap exists between workers in the high-high group and those in the low-low group or the high-low group. On average, the job satisfaction of the first group is higher by 1.47 points and 1.33 points compared to the low-low and high-low groups, respectively. The results in Table 4 indicate that these differences persist even after controlling for differences across workers in individual, occupational, and workplace characteristics.

The regression results above are based on the assumption that the relationship between job satisfaction and the individual, occupational and workplace characteristics is the same across the groups. That is, the estimated coefficients are restricted to being the same for each group. It is possible, however, that the coefficients might also vary across groups. One interpretation of such variation could be that the groups react to or "value" their personal, job or workplace characteristics differently. Perhaps, for example, workers in the high-high group may on average value working conditions more highly than do workers in the low-low group, which consequently increases their average job satisfaction. This would be evidenced by a difference in the regression coefficient on the workplace working conditions variable in group-specific regressions. Such regressions form the basis for the Blinder-Oaxaca decomposition.

The aim of the Blinder-Oaxaca decomposition analysis is to determine the extent to which the differences in the average job satisfaction between the high-high group and the other groups can be explained by (i) differences in personal, occupational or workplace characteristics (endowment effect), (ii) differences in the way that employees 
react to (or "value") those characteristics (coefficient effect), and (iii) the interaction of the two. Table 5 presents the results of the decomposition. The table reports the mean differential in the job satisfaction variable and the percentages associated with the part of the differential that is due to (i) group differences in the characteristics, (ii) in the coefficients, and (iii) in the interaction of the two.

Table 5. Blinder-Oaxaca decomposition results, HRM exposure-perception groups

\begin{tabular}{|c|c|c|c|c|c|c|}
\hline & \multicolumn{2}{|c|}{ HH versus LL } & \multicolumn{2}{|c|}{$\mathrm{HH}$ versus $\mathrm{HL}$} & \multicolumn{2}{|c|}{ HH versus LH } \\
\hline & Contribution & $\%$ & Contribution & $\%$ & Contribution & $\%$ \\
\hline Differences & $1.47 * * *$ & & $1.33^{* * *}$ & & -0.09 & \\
\hline $\begin{array}{l}\text { Part due to } \\
\text { differences in } \\
\text { means }^{1}\end{array}$ & 0.13 & 8.71 & 0.02 & 1.63 & 0.02 & -27.15 \\
\hline $\begin{array}{l}\text { Part due to } \\
\text { differences in } \\
\text { coefficients }{ }^{2}\end{array}$ & $1.45^{* * *}$ & 98.80 & $1.27 * * *$ & 95.35 & 0.00 & -7.36 \\
\hline $\begin{array}{l}\text { Part due to } \\
\text { interaction }^{3}\end{array}$ & -0.11 & -7.51 & 0.04 & 3.02 & -0.13 & 134.51 \\
\hline
\end{tabular}

Notes: *Statistically significant at the .10 level; $* *$ at the .05 level; $* * *$ at the .01 level.

${ }^{1}$ endowment effect; ${ }^{2}$ coefficient effect; ${ }^{3}$ interaction term

The decomposition shows that for the low-low group and the high-low group, the differences in the average level of job satisfaction with the high-high group are mainly due to differences in the coefficients. Therefore, applying the coefficients of the high-high to the employees who have a low HRM perception, irrespective of the exposure level, would significantly increase their job satisfaction. One interpretation of this result is that the degree to which employees positively perceive HRM practices modifies the association between job satisfaction and personal, occupation and workplace characteristics. This result reveals a link between the degree of HRM perception on the way employees react to their personal, job and workplace characteristics and supports Hypothesis $4 \mathrm{~b}$ for the perception side. In contrast, Hypothesis $4 \mathrm{a}$ is not supported for the perception side. The decomposition shows no significant links between the degree of HRM exposure and the way employees react to their personal, job and workplace characteristics.

\subsection{Robustness checks ${ }^{11}$}

For the three first steps of our estimation strategy, robustness check regressions were performed to see if the results presented in Tables 3 and Table 4 are sensitive to the empirical strategy or the threshold choice made to distinguish high versus low exposure and perception groups. First, we estimate ordered Probit instead of linear 
regressions. The results are identical to those presented in Tables 3 and 4. Second, we distinguish the high exposure and the high perception groups from the low using the mean value taken by the bundles instead of the median value as a cut-off. The sign and significance of the results of Table 3 and 4 are mostly the same. One exception is that the Exposure High (EH) variable in the regression of job satisfaction in Table 3 - Model A is no longer significant at the 0.10 level $(\mathrm{p}=0.14)$. Third, we run the regressions and the decomposition analysis without clustering the standard errors. The main results of Tables 3, 4 and 5 remain. Fourth, we utilized an alternative decomposition method, the twofold decomposition method (Neumark, 1988). The qualitative results of Table 5 are mostly the same.

\section{Discussion and conclusion}

Three major conclusions emerge from this paper. First, the integration of employer and employee views regarding the HRM set of practices gives new insights into the way HRM practices improve employee satisfaction. In particular, the implementation of a high number of HRM practices by the employer that expose employees to HRM is not sufficient to increase their job satisfaction. It is the employees' perception about HRM practices through an effective participation in a high number of HRM practices that improve their job satisfaction. Second, based on a Blinder-Oaxaca decomposition, we find that employee HRM perception affects the value employees place on their personal, job and workplace characteristics. Thus, applying the coefficients of the high exposure and high perception to the employees who have a low level of HRM perception, irrespective of the exposure level, would increase their job satisfaction. Third, grounded in analytical frameworks that assume that employees respond positively to a positive work environment (e.g. job demands/resources, mutual gains) and the importance on HRM internal fit, the last major result of this article is that HRM research needs to give greater attention to the employees' perception of HRM practices in the assessment of the links between bundles of HRM practices and employees' attitudes. The paper makes important contributions to the academic literature in several ways. First, while most existing empirical studies analysed separately either the relationships between job satisfaction and HRM exposure or the relationships with HRM perception (Boon et al., 2019), we integrate the two perspectives. Therefore, even if various studies have separately tested and confirmed a positive relationship between bundles of HRM and job satisfaction (e.g. Chowhan et al., 2016; Huang et al., 2016; Martin, 2018; White and Bryson, 2013), multi-level analyses remain scarce (Den Hartog et al., 2013; Edgar and Gear, 2005). This study addresses this multi-level issue and confirms the important role of employee perception. From a theoretical perspective this 
paper provides new insights regarding the internal fit of HRM bundles and the need for an alignment of employers' and employees' views on the HRM system in order to strengthen employees' satisfaction. Second, the employer/employee data we used covers a large number of firms and employees representative of the private sectors of the economy of Luxembourg, allowing the results to be generalized to all private workplaces in Luxembourg. This issue is considered as the main limitation of earlier multi-level analyses conducted on very small sample and specific sectors (Den Hartog et al., 2013; Edgar and Gear, 2005). Third, the analysis employing multiple regression methods provides much needed controls on personal, occupational or workplace characteristics that were missing in the existing studies. Fourth, the use of the Oaxaca-Blinder decomposition method allows us to more fully explore the determinants of differences in job satisfaction between groups of employees who face different levels of HRM bundle exposure and HRM bundle perception.

\section{Practical implications}

The results also provide practical managerial implications for employers as job satisfaction is a key mediating variable between the adopted HRM system and business performance. Even if all employees do not have the same role in the value creation process of the firm, the results indicate that managers should take more account of the perception of the staff regarding the HRM system they have adopted to improve their well-being. Employees need to participate in training, to exercise voice during meetings with managers, to participate in the decision-making process at the team level, and to strengthen their skills in order to be more satisfied in place no matter the level of actual HRM implemented by managers. Moreover, according to the HR attributions approach, the perception of employees depends on the motives they believe are behind the implementation of HRM practices. As employees need to adhere to the HRM system to exhibit a positive response to it, managers should take the time to explain to employees the reasons for HRM implementation and pursue an employee enhancement motive when they adopt HRM practices. The room for that should be grounded on an environment that encourages and gives more voice to the staff. This can be done by strengthening workplace voices practices such as more regular meetings between management and the staff, more quality circles or the recognition of workers representatives as underlined by Bryson et al. (2007). In doing so, managers will be able to modify the way employees value a given job situation. Indeed, faced with given personal, occupational and workplace characteristics, employees who participate in more HRM practices are more satisfied with their work. Employers thus are able to make personal, occupational and 
workplace characteristics more enjoyable by ensuring that their employees endorse the HRM practices implemented in the firm.

\section{Limitations and future research directions}

Despite the various contributions provided by this analysis, it is not without empirical limitations, which may be overcome by future research. First, the empirical results of the present paper are, as in most existing studies, based on the use of single cross-sectional data which is "an efficient and invaluable go-to tool for investigating important organizational phenomena." (Spector, 2019, p. 136). Our findings provide then the strength of conditional correlations between the bundle of HRM practices and job satisfaction, but this kind of data prevents researchers from identifying causal relationships. Nevertheless, even if the analytical framework presented in the paper clearly supports the influence of HRM on job satisfaction and not a reverse link, employer/employee longitudinal data could provide causal relationships and improve the understanding of the timing and the order of the adoption of HRM practices in firms.

Second, even if we show that the existence of a potential self-selection of individuals attracted by high-HRM firms may have minimal impact on our findings as both high and low worker perceptions of HRM are distributed across workplaces independent of the level of exposure (see Table 2), longitudinal data with information regarding individuals' knowledge about HRM before employment with their current firm could provide a test regarding this self-selection issue. In addition, longitudinal data would allow controls for unobserved characteristics of workers that might affect their probability of employment in firms of a given type.

Third, the empirical results are based on employer/employee data from a single country collected in 2013. While the analysis contributes to the knowledge generated by existing papers on the topic (see for instance, Den Hartog et al., 2013; Edgar and Geare, 2005), similar exposure/perception analyses with more recent employer/employee data in other countries and regions would be useful to substantiate or refute our findings. Fourth, while our employer/employee data allows us to control for many firm-level and employee-level characteristics which are pre-determined and not affected by the HRM practices, which prevent us from capturing spurious correlation between the bundle of HRM practices and job satisfaction (due to unobserved or unmeasured variables that are correlated with these two dimensions) more detailed data could provide deepen analyses. For instance, although we use employer/employee data representative of employees and of employers of the private sector, the employee 
sample was not designed to ensure each employer has a representative set of employees included in the sample hindering more precise analyses at the employer level to learn new knowledge about HRM systems fine-tuned by employers (e.g. as underlined by Kaufman, 2012).

Finally, we provide results on one of the facets of the internal fit approach (e.g. Kepes and Delery, 2009) about the alignment of employers' and employees' views about HRM ('within-HRM system vertical fit'). Other perspectives of internal fit that deal with 'powerful connections' and 'deadly combinations' of HRM practices in bundles ('inter-HRM activity area fit') and the other facets ('intra-HRM activity area fit', 'between-HRM system fit'), however, as well as the external fit, are not addressed in this study and should be the focus of future research.

\section{Acknowledgements}

This research is part of the TWAIN project supported by the National Research Fund, Luxembourg (contract FNR/C11/LM/1196209) and by core funding for LISER (formerly CEPS/INSTEAD) from the Ministry of Higher Education and Research of Luxembourg. The authors thank Amparo Nagore Garcia (University of Valencia), Bertrand Verheyden (LISER), and various seminar and conference audiences for helpful comments. We thank the National Ministry of Social Security of Luxembourg and LISER for sponsoring and providing access to the 'Survey on Working Conditions and Quality of Work Life' (QVT). 


\section{End notes}

${ }^{1}$ Regarding the relationships between HRM and business performance, many studies highlight a positive relationship across sectors, sample characteristics, practices studied, and business performance outcomes (e.g. Buller and McEvoy, 2012; Saridakis et al., 2017). Nevertheless, some HRM practices have been shown to be negatively linked with business performance outcomes (e.g. Zeytinoglu et al., 2017). It should be thus noticed that there is no 'one size fit all' for the adoption of HRM practices by firms to increase the business performance, and managers are crafts that need to learn through practice and experience to choose the best HRM system for their organization (e.g. Adnan et al., 2011; Kaufman, 2010; 2012).

${ }^{2}$ Hereafter, we will refer to this perspective using the term HRM exposure.

${ }^{3}$ Hereafter, we will refer to this perspective using the term HRM perception.

${ }^{4}$ This mean can appear to be quite low compared to existing European figures such as EU-SILC. Nevertheless, it should be noted that the scale from the Employer-Employee survey (0-10) is not directly comparable to those used in EU-SILC (1-10). Moreover, the data used in this paper only covers the private sector, contrary to EU-SILC, and takes into account cross-border workers whereas EU-SILC doesn't. In EU-SILC data, the level of job satisfaction observed in Luxembourg is comparable to the mean in EU-28 of about 7 (https://goo.gl/aJgQnB).

${ }^{5}$ Luxembourg appears to have the highest amount of specific requirements for individual and collective dismissal. The OECD indicator of Employment Protection Legislation (EPL) provides a synthetic indicator of the strictness of regulation on dismissals on regular contracts. For a comparison, in 2013, this indicator is 2.25 in Luxembourg versus 1.10 in the UK or 0.26 in the US (https://goo.gl/gZjoFN).

${ }^{6}$ The robustness checks sub-section 4.4 provides details about the test of the sensitivity of the results to different group allocations due to the choice of the cut-off.

${ }^{7}$ In our sample, the average number of employees is 3 for workplaces with 15-49 employees, 5 for workplaces with 50-99 employees, 8 for workplaces with 100-249 employees and 54 for workplaces with 250 or more employees.

\footnotetext{
${ }^{8}$ The estimated coefficients from this step are available upon request.

${ }^{9}$ The results of all variables included in the regressions are available upon request.
} 


\footnotetext{
${ }^{10}$ The estimated coefficients for all variables included in the regressions are available upon request.

${ }^{11}$ All robustness check regressions are available upon request.
}

\section{References}

Adnan Z, Abdullah HS, Ahmad J (2011) Direct influence of human resource management practices on financial performance in Malaysian R\&D companies. World Review of Business Research 1(3): 61-77.

Appelbaum E, Bailey T, Berg P et al. (2000) Manufacturing Advantage: Why High-Performance Work Systems Pay Off. Ithaca, NY: ILR Press.

Arundel A, Lorenz E, Lundvall BÅ et al. (2007) How Europe's economies learn: A comparison of work organization and innovation mode for the EU-15. Industrial and Corporate Change 16(6): 1175-1210.

Askenay P and Caroli E (2010) Innovative work practices, information technologies and working conditions: evidence for France. Industrial Relations 49(4): 544-565.

Bakker AB and Demerouti E (2007) The job demands-resources model: state of the art. Journal of Managerial Psychology 22(3): 309-328.

Barney J (1991) Firm resources and sustained competitive advantage. Journal of Management 17(1): 99-120.

Barney JB and Wright PM (1998) On becoming a strategic partner: The role of human resources in gaining competitive advantage. Human Resource Management Journal 37(1): 31-46.

Batt R (2004) Who benefits from teams? Comparing workers, supervisors, and managers. Industrial Relations, 43(1): 183-212.

Becker BE, Huselid MA, Pickus PS and Spratt MF (1997) HR as a source of shareholder value: Research and recommendations. Human Resource Management 36(1): 39-47.

Becker BE and Huselid MA (1998) High Performance Work Systems and firm performance: A synthesis of research and managerial implications. In: Rowland KM and Ferris GR (eds), Research in Personnel and Human Resources Management, Vol. 16. Greenwich, Connecticut: JAI Press, pp. 53-101. 
Blinder AS (1973) Wage discrimination: reduced form and structural estimates. The Journal of Human Resources 8(4): 436-455.

Böckerman P, Bryson, A and Ilmakunnas P (2012) Does high involvement management improve worker wellbeing? Journal of Economic Behavior and Organization 84(2): 660-680.

Boon C, Den Hartog DN and Lepak DP (2019) A Systematic review of human resource management systems and their measurement. Journal of Management 45(6): 2498-2537.

Bowen DE and Ostroff C (2004) Understanding HRM-performance linkages: The role of the 'strength' of the HRM system. Academy of Management Review 29(2): 203-221.

Boxall P and Macky K (2009) Research and theory on high-performance work systems: Progressing the highinvolvement stream. Human Resource Management Journal 19(1): 3-23.

Boxall P and Macky K (2014) High-involvement work processes, work intensification and employee well-being. Work, employment and society 28(6): 963-984.

Brown S, McHardy J, McNabb R et al. (2011) Workplace performance, worker commitment, and loyalty. Journal of Economics and Management Strategy 20(3): 925-955.

Bryson A, Gomez R, Kretschmer T and Willman P (2007) The diffusion of workplace voice and high-commitment human resource management practices in Britain, 1984-1998. Industrial and Corporate Change 16(3): 395-426. Bryson A and White M (2016) Not so dissatisfied after all? The impact of union coverage on job satisfaction. Oxford Economic Papers 68(4): 898-919.

Buller P and McEvoy GM (2012) Strategy, human resource management and performance: Sharpening line of sight. Human Resource Management Review 22(1): 43-56.

Chowhan J, Zeytinoglu IU and Cooke GB (2016) Immigrants and job satisfaction: Do high performance work systems play a role? Economic and Industrial Democracy 37(4): 690-715.

Clark AE (1997) Job satisfaction and gender : Why are women so happy at work? Labour Economics 4(4): 341372. 
Clark AE (2001) What really matters in a job? Hedonic measurement using quit data. Labour Economics 8(2): 223-242.

Clark A, Oswald A and Warr P (1996) Is job satisfaction U-shaped in age? Journal of Occupational and Organizational Psychology 69(1): 57-81.

Combs J, Liu Y, Hall A et al. (2006) How much do high-performance work practices matter? A meta-analysis of their effects on organizational performance. Personnel Psychology 59(3): 501-528.

Daymont TN and Andrisani PJ (1984) Job preferences, college major, and the gender gap in earnings. The Journal of Human Resources 19(3): 408-428.

Den Hartog DN, Boon C, Verburg RM et al. (2013) HRM, communication, satisfaction, and perceived performance: A cross-level test. Journal of Management 39(6): 1637-1665.

Edgar F and Geare A (2005) HRM practice and employee attitudes: Different measures - different results. Personnel Review 34(5): 534-549.

Eriksson T and Kristensen N (2014) Wages or fringes? Some evidence on trade-offs and sorting. Journal of Labor Economics 32(4): 899-928.

Ernst Kossek E and Ozeki C (1998) Work-family conflict, policies, and the job-life satisfaction relationship: A review and directions for organizational behavior-human resources research. Journal of Applied Psychology 83(2): 139-149.

Frick B, Götzen U and Simmons R (2013) The hidden costs of high performance work practices: Evidence from a large German steel company. Industrial and Labor Relations 66(1): 198-224.

Gazioglu S and Tansel A (2006) Job satisfaction in Britain: Individual and job related factors. Applied Economics 38(10): 1163-1171.

Gerhart, B. (2007). Horizontal and vertical fit in human resource systems. In: Ostroff C and Judge TA (eds), Perspectives on organizational fit. Hillsdale, New Jersey: Erlbaum, pp. 317-350.

Godard J (2001) High performance and the transformation of work? The implications of alternative work practices for the experience and outcomes of work. Industrial and Labor Relations Review 54(4): 776-805.

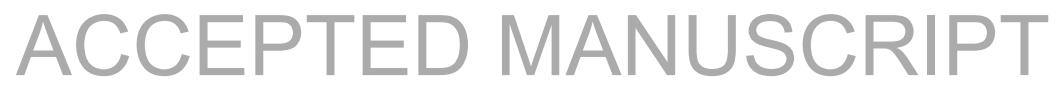


Godard J (2004) A critical assessment of the high-performance paradigm. British Journal of Industrial Relations 42(2): 349-378.

Godard J (2010) What is best for workers? The implications of workplace and human resource management practices revisited. Industrial Relations 49(3): 466-488.

Gould-Williams JS (2003) The importance of HR practices and workplace trust in achieving superior performance: a study of public-sector organizations. International Journal of Human Resource Management 14(1): $28-54$.

Gould-Williams JS (2007) HR practices, organizational climate and employee outcomes: Evaluating social exchange relationships in local government. International Journal of Human Resource Management 18(9): 16271274.

Green F (2006) Demanding work. The paradox of job quality in the affluent society. Princeton, New Jersey: Princeton University Press.

Green C and Heywood JS (2008) Does performance pay increase job satisfaction? Economica 75(300): 710-728.

Guest DE (1999) Human resource management - The workers verdict. Human Resource Management Journal $9(3): 5-25$.

Guest DE (2017) Human resource management and employee well-being: Towards a new analytic framework. Human Resource Management Journal 27(1): 22-38.

Hair JF, Tatham RL, Anderson RE et al. (2006) Multivariate data analysis (5th ed.). Englewood Cliffs, NJ: Pearson Prentice Hall.

Hanaysha J and Tahir PR (2016) Examining the effects of employee empowerment, teamwork, and employee training on job satisfaction. Procedia - Social and Behavioral Sciences 219: 272-282.

Hauret L and Williams DR (2017) Cross-national analysis of gender differences in job satisfaction. Industrial Relations 56(2): 203-235.

Heffernan M and Dundon T (2016) Cross-level effects of high-performance work systems (HPWS) and employee well-being: the mediating effect of organisational justice. Human Resource Management journal 26(2): $211-231$.

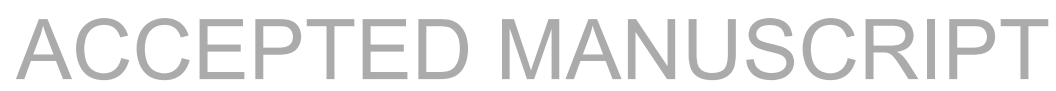


Hewett R, Shantz A, Mundy J and Alfes K (2018) Attribution theories in Human Resource Management research: a review and research agenda. The International Journal of Human Resource Management 29(1): 87-126.

Hoque K (2000) Human resource management and performance in the UK hotel industry. British Journal of Industrial Relations 37(3): 419-443.

Huang LC, Ahlstrom D, Lee A Y-P, Chen S-Y and Hsieh M-J (2016) High performance work systems, employee well-being, and job involvement: An empirical study. Personnel Review 45(2): 296-314.

Huselid MA (1995) The impact of human resource management practices on turnover, productivity, and corporate financial performance. Academy of Management Journal 38(3): 635-672.

Jiang K, Lepak DP, Hu J, and Baer JC (2012) How does human resource management influence organizational outcomes? A meta-analytic investigation of mediating mechanisms. Academy of Management Journal 55(6): $1264-1294$.

Kalmi P and Kauhanen A (2008) Workplace innovations and employee outcomes: Evidence from Finland. Industrial Relations 47(3): 430-459.

Katou AA and Budhwar PS (2006) Human resource management systems and organizational performance: A test of a mediating model in the Greek manufacturing context. International Journal of Human Resource Management 17(7): 1223-1253.

Kaufman BE (2010) SHRM Theory in the post-Huselid era: Why it is fundamentally misspecified. Industrial Relations 49(2), 286-313.

Kaufman BE (2012) Strategic human resource management research in the United States: A failing grade after 30 years? Academy of Management Perspectives 26(2): 12-36.

Kehoe RR and Wright PM (2013) The impact of high-performance human resource practices on employees' attitudes and behaviors. Journal of Management 39(2): 366-391.

Kepes S and Delery JE (2009) HRM systems and the problem of internal fit. In: Boxall P, Purcell J and Wright PM (eds) The Oxford Handbook of Human Resource Management. Oxford: Oxford University Press, pp. 385404. 
Kifle T (2014) Do comparison wages play a major role in determining overall job satisfaction? Evidence from Australia. Journal of Happiness Studies 15(3): 613-638.

Koys DJ (1991) Fairness, legal compliance, and organizational commitment. Employee Responsibilities and Rights Journal 4(4): 283-291.

Kröll C and Nüesch S (2019) The effects of flexible work practices on employee attitudes: Evidence from a largescale panel study in Germany. The International Journal of Human Resource Management 30(9): 1505-1525.

Lawler EE (1986) High-Involvement Management. San Francisco, CA: Jossey-Bass.

Liao H, Toya K, Lepak DP et al. (2009) Do they see eye to eye? Management and employee perspectives of high performance work systems and influence processes on service quality. Journal of Applied Psychology 94(2): 371391.

Macduffie JP (1995) Human resource bundles and manufacturing performance: Organizational logic and flexible production systems in the world auto industry. Industrial and Labor Relations Review 48(2): 197-221.

Macky K and Boxall P (2007) The relationship between "high-performance work practices" and employee attitudes: An investigation of additive and interaction effects. International Journal of Human Resource Management 18(4): 537-567.

Markoulli M, Lee CISG, Byington E and Felps WA (2017) Mapping human resource management: Reviewing the field and charting future directions. Human Resource Management Review 27(3): 367-396.

Martin L (2018) How to retain motivated employees in their jobs? Economic and Industrial Democracy 34(1): $25-41$.

McGovern P, Hill S, Mills C et al. (2007) Market, class, and employment. Oxford: Oxford University Press.

MEADOW Consortium (2010) The MEADOW Guidelines. Project funded within the 6th Framework Programme of the European Commission's DG Research. Grigny, France.

Mohr RD and Zoghi C (2008) High-involvement work design and job satisfaction. Industrial and Labor Relations Review 61(3): 275-296. 
Neumark D (1988) Employers' discriminatory behaviour and the estimation of wage discrimination. Journal of Human Resources 23(3): 279-295.

Nie D, Lamsa AM and Pucetraite R (2018) Effects of responsible human resource management practices on female employees' turnover intentions. Business Ethics: A European Review 27(1): 29-41.

Nishii LH, Lepak DP and Schneider B (2008) Employee attributions of the 'why' of HR practices: their effects on employee attitudes and behaviors, and customer satisfaction. Personnel Psychology 61(3): 503-545.

Oaxaca RL (1973) Male-female wage differentials in urban labor markets. International Economic Review 14(3): 693-709.

Ogbonnaya C, Daniels K, Connolly S and van Veldhoven M (2017) Integrated and isolated impact of highperformance work practices on employee health and well-being: A comparative study. Journal of Occupational Health Psychology 22(1): 98-114.

Osterman P (2000) Work reorganization in an era of restructuring: Trends in diffusion and effects on employee welfare. Industrial and Labor Relations Review 53(2): 179-196.

Park HJ, Mitsuhashi H, Fey CF et al. (2003) The effect of human resource management practices on Japanese MNC subsidiary performace: A partial mediating model. International Journal of Human Resource Management 14(8): 1391-1406.

Peccei RE and Van de Voorde FC (2019) The application of the multilevel paradigm in human resource management outcomes research: Taking stock and going forward. Journal of Management 45(2): 786-818.

Raab R (2020) Workplace perception and job satisfaction of older workers. Journal of Happiness Studies 21(March): 943-963.

Ramsay H, Scholarios D and Harley B (2000) Employees and high-performance work systems: Testing inside the black box. British Journal of Industrial Relations 38(4): 501-531.

Rousseau D (1995) Psychological contracts in organisations: Understanding the written and unwritten agreements. London: Sage.

Saridakis G, Lai Y and Cooper CL (2017) Exploring the relationship between HRM and firm performance: A meta-analysis of longitudinal studies. Human Resource Management Review 27(1): 87-96.

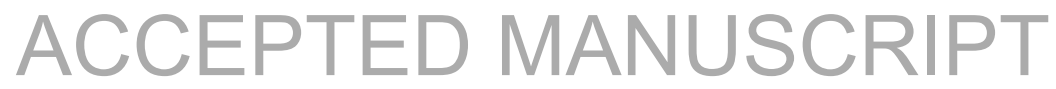


Schaufeli WB and Bakker AB (2004) Job demands, job resources, and their relationship with burnout and engagement: A multi-sample study. Journal of Organizational Behavior 25(3): 293-315.

Sousa-Poza A and Sousa-Poza AA (2000) Taking another look at the gender/job satisfaction paradox. Kyklos 53(2): 135-151.

Spector PE (2019) Do not cross me: Optimizing the use of cross-sectional designs. Journal of Business and Psychology 34(2): 125-137.

Sturges J, Conway N, Guest D et al. (2005) Managing the career deal: The psychological contract as a framework for understanding career management, organizational commitment and work behavior. Journal of Organizational Behavior 26(7): 821-838.

Stutzer A and Frey BS (2008) Stress that doesn't pay: The commuting paradox. Scandinavian Journal of Economics 110(2): 339-366.

Suazo MM, Martínez PG and Sandoval R (2009) Creating psychological and legal contracts through human resource practices: A signaling theory perspective. Human Resource Management Review 19(2): 154-166.

Subramony M (2009) A meta-analytic investigation of the relationship between HRM bundles and firm performance. Human Resource Management 48(5): 745-768.

Tabvuma V, Georgellis Y and Lange T (2015) Orientation training and job satisfaction: a sector and gender analysis. Human Resource Management 54(2): 303-321.

Van de Voorde K and Beijer S (2014) The role of employee HR attributions in the relationship between highperformance work systems and employee outcomes. Human Resource Management Journal 25(1): 62-78.

Van de Voorde K, Paauwe J and Van Veldhoven M (2012) Employee well-being and the HRM-performance relationship: a review of quantitative studies. International Journal of Management Reviews 14(4): 391-407.

Warr PB (1987) Work, unemployment and mental health,. Oxford: Clarendon Press.

White M and Bryson A (2013) Positive employee attitudes: How much human resource management do you need? Human Relations 66(3): 385-406. 
Wood S (1999). Human resource management and performance. International Journal of Management Reviews 1(4): $367-413$.

Wood S, Van Veldhoven M, Croon M et al. (2012) Enriched job design, high involvement management and organizational performance: The mediating roles of job satisfaction and well-being Human Relations 65(4): 419446.

Zelenski JM, Murphy SA and Jenkins DA (2008) The happy-productive worker thesis revisited. Journal of Happiness Studies 9(4): 521-537.

Zeytinoglu IU, Chowhan J, Cooke GB and Mann S (2017) An ill-informed choice: Empirical evidence of the link between employers' part-time or temporary employment strategies and workplace performance in Canada. International Journal of Human Resource Management 28(19): 2713-2737. 